\section{Halim Rane, Jacqui Ewart, John Martinkus: Media Framing of the Muslim World. Conflicts, Crises and Contexts. Palgrave Macmillan, 2014, ISBN: 9781137334817, p.216.}

KOME - An International Journal of Pure Communication Inquiry Volume 4 Issue 1, p. 89-91. (C) The Author(s) 2016 Reprints and Permission: kome@komejournal.com

Published by the Hungarian Communication Studies Association DOI: 10.17646/KOME.2016.17

\author{
Lilla Vicsek \\ Corvinus University of Budapest, Institute of Sociology and Social Policy, Hungary
}

Portrayals of Muslim people proliferate in many media outlets in the non-Muslim world. Yet, as Halim Rane, Jacqui Ewart and John Martinkus; authors of the book Media Framing of the Muslim World argue, despite the number of news pieces dealing with this topic, the type of stories that tend to be told are rarely varied, but instead are restricted to a few kinds of interpretative packages or "frames" (Entman 1993). Despite the variety in cultures, societies, experiences, ethnicities of the people of the Muslim world, these distinctions are often neglected in the media. Muslims are associated in the media with terrorists, extremists, hostility toward the West, and asylum seekers.

The book gives a rich overview of the literature, drawing on a wealth of previous research on the topic, as well as presenting the authors' own research from Australia while also detailing the experiences of one of the authors as a journalist in Iraq and Afghanistan.

In the introduction, the authors introduce the main ideas of the book as well as the theoretical underpinnings (news values, framing, agenda-setting, orientalism). The later chapters of the book discuss the following topics: 1. information about the Muslim World, the issue of integration of Muslims in the West; 2. portrayal of the Muslim world in Western media; 3. how it was possible to do reporting in Iraq and Afghanistan and how that influenced the nature of the reporting; 4. Muslim asylum seekers in Western countries (including research results on how they are portrayed in the Australian media and how the Australian public views them); 5. the nature of coverage of terrorist suspects and what influences this coverage; 6. the role of social and mass media in the events of the Arab Spring; 7. freedom of expression in Islam and considering cases where the work of Western journalists/artists have triggered outcry from part of the Muslim world; 8. results of a media analysis and focus group research conducted by the authors of the book in Australia looking at the media portrayal and audience reactions a decade after the terrorist attacks of September $11^{\text {th }} 2001$.

For the present reviewer, two main questions were relevant when assessing the book: 1 . Looking at the theoretical relevance of the book: What from a theoretical perspective is new in this book? What is an important result for the discipline of communication? 2. About the empirical information: How does it add to the reader's existing knowledge on the topics of the Muslim world and the media? Is there substantially new information? Something surprising?

Regarding question one, the book relies on the connections between media influence on the theoretical background of media framing and agenda-setting. These well-established approaches to media content and influence are emphasized, with the book favoring Entman's 
(1993) framing approach. Both framing and agenda setting are interpreted as theories showing that media is influencing audience opinions. Hardly any emphasis is placed on other media influence approaches in the book, some of which have questioned the assertions of framing and agenda setting. A more sophisticated theoretical background could have taken into account these debates on media effects within Media Studies, but could still have argued that in case of topics where most of the audience's information comes from the media, the media's role could be especially important. It is also relevant that some studies have pointed to the fact that just because we get all of our information from the media on a topic, it does not necessarily mean that the media has great power over us. For example, we can base our arguments on analogies from other topics that we are familiar with. Moreover, if we do not trust the media that is also another factor mitigating media influence. The last is mentioned in an empirical study in the book, along with some other mitigating factors, but it is not integrated into the theoretical background. In summary, the theoretical background does not seem to bring too much novelty to the field and is not nuanced enough in its approach. Ultimately, the theoretical background is not integrated into the analysis segments sufficiently to strengthen the sections.

To answer the second question, after reading the book I did not feel that I saw the issue in a fundamentally new light. Much of the main message of the book - that media often associates Muslims with extremists, terrorists, a culture intrinsically hostile toward the West, which is not representative of the "reality" - is not surprising. Still, there is a wealth of data in the book, some of which can be considered the main strengths of the book. For example, results from survey research projects conducted by the Pew Research Center (2013) are discussed in the book. Thirty-eight thousand Muslims were asked in 39 countries about their views on religion, non-Muslims, etc. Also, even if there is no big surprise in reading the book, there are some smaller surprises. I found the research results on Australia interesting, particularly since many of the readers would not be familiar with current socio-political climate. An analysis of the Australian media coverage of September $11^{\text {th }}$ a decade later also hints at a possible shift in media portrayal, toward a less hostile media presentation. The audience analysis the authors conducted there, which touches upon the sensitivities of Muslim audience members is also interesting, although a great constraint is the very small sample size. Another part, which can potentially grab attention, is the experiences of one of the authors of the book as a journalist on the field. It shows how the violence in Iraq constrained the possibilities of showing certain types of stories, certain viewpoints as major media organizations had to operate from secured fortresses, and venturing outside of these fortresses was dangerous.

The reader needs to take into account that the book was published in 2014, as a result the events since then have yet to be covered in the book.

It seems that the topic of gender and the Muslim world was not given enough attention in the book (it was mentioned that sometimes in the West the Muslim world is presented as oppressing women, but this theme was not really expanded upon within the book).

The presentation of research data could have been more reader friendly, with graphs, tables, etc., as after a while one can get a bit lost in the many survey results that are just discussed as part of the main text. (I looked at the Pew Research Center's (2013) original presentation of the results, and that is much more accessible to the reader, and has a lot of graphs, and instantly I was better able to understand their presentation than the same results as they are discussed in the book). Still, it is a great strength of the book is that it is a rich sourcebook: it summarizes a wide range of literature, providing a rich starting point for anyone interested in data related to this topic. 


\section{References}

Entman, R. (1993): Framing: Towards Clarification of a Fractured Paradigm. Journal of Communication, 43 (4), 51-58. CrossRef

Pew Research Center (2013): The World's Muslims: Religion, Politics and Society, http://www.pewforum.org/2013/04/30/the-worlds-muslims-religion-politicssociety-overview/, date accessed: 10. December, 2015. 